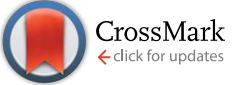

Cite this: RSC Adv., 2015, 5, 66727
Received 8th June 2015

Accepted 30th July 2015

DOI: $10.1039 / \mathrm{c} 5 \mathrm{ra10855a}$

www.rsc.org/advances

\title{
The role of xylulose as an intermediate in xylose conversion to furfural: insights via experiments and kinetic modelling
}

\author{
O. Ershova, ${ }^{a}$ J. Kanervo, ${ }^{b}$ S. Hellsten ${ }^{a}$ and H. Sixta*a
}

An experimental work has been performed to study the relevance of xylulose as an intermediate in xylose conversion to furfural in aqueous solution. The furfural formation was investigated at the temperature range from 180 to $220{ }^{\circ} \mathrm{C}$ during non-catalyzed and acid-catalyzed conversion of xylose in a stirred microwaveassisted batch reactor. The separate experiments on xylulose and furfural conversions were carried out under similar conditions. The maximum furfural yields obtained from xylose were $48 \mathrm{~mol} \%$ and $65 \mathrm{~mol} \%$ for the non-catalyzed and the acid-catalyzed processes, respectively. It was shown that the furfural yield is significantly lower from xylulose than from xylose. Furthermore, the effects of initial xylose concentration and the formation of xylulose were investigated in a mechanistic modeling study. A new reaction mechanism was developed taking into account the xylulose formation from xylose. Based on the experimental results and the proposed reaction model, it was concluded that xylose isomerization to xylulose with subsequent furfural formation is not a primary reaction pathway. The obtained kinetic parameters were further used for plug flow reactor simulations to evaluate furfural yields achievable by an optimized continuous operation.

\section{Introduction}

Furfural is a platform chemical utilized in the chemical industry for synthesizing solvents, adhesives, medicines, and plastics. ${ }^{1}$ It is mainly obtained in acidic aqueous solution by direct dehydration of pentosans derived from different biomass such as corncob, bagasse, wheat and rice straw. Xylose is the most utilized monosaccharide in furfural production. It is a pentose which can be formed either by direct degradation of polymeric xylan in lignocellulosic material or by depolymerization of the solubilized oligomeric xylan. ${ }^{2}$ In addition, several studies describe the furfural formation from other pentoses ${ }^{3-6}$ or hexoses. ${ }^{5}$ Furfural can be also obtained as a by-product of different biomass treatment processes. ${ }^{7-9}$

Currently, furfural is produced industrially with about $50 \mathrm{~mol} \%$ yield $^{10,11}$ utilizing sulfuric or hydrochloric acid as a catalyst. The replacement of these wasteful and energy-inefficient mineral acid catalysts by solid acid catalysts bearing different acidic functionalities, which are able to achieve a sufficient improving in the furfural yield, has a growing interest. However, an understanding of the reaction pathways as well as the kinetics of furfural formation in aqueous media in the presence or absence of acids is crucial for the successful development of the

${ }^{a}$ Department of Forest Products Technology, Aalto University, Finland. E-mail: herbert. sixta@aalto.fi

${ }^{b}$ Department of Biotechnology and Chemical Technology, Aalto University, Finland efficient catalytic system and the obtaining of the target product in high yields.

Currently, the kinetics of furfural formation under different conditions are widely studied in order to create a scientific basis for improving the production efficiency. However, it is challenging to reconcile all the published kinetic data presented in the literature due to the different reaction conditions and conflicting modelling approaches used. Different reaction mechanisms of the furfural formation from pentoses have been proposed in scientific literature based on different analysis and reaction modellings. In the majority of research papers, the kinetics of xylose dehydration to furfural is based on a simplified reaction scheme with a direct pathway from xylose to furfural. ${ }^{12-14}$ The current knowledge on the kinetics of side and loss reactions has been identified as insufficient as well. ${ }^{15}$

One of the open questions in the furfural formation reaction is whether the mechanism proceeds via a cyclic or an acyclic form of xylose. Antal and co-workers claim that the furfural formation proceeds from the pyranose form of xylose without a ring opening stage. ${ }^{16,17}$ However, most researchers have adopted a reaction mechanism hypothesis that involves the formation of an acyclic xylose form, even though this mechanism is not able to fully explain the formation of some side products. ${ }^{4,15}$ Antal et al. ${ }^{17}$ have also proposed the formation of both acyclic and cyclic forms of xylose at temperatures above $250{ }^{\circ} \mathrm{C}$.

Irrespective whether the reaction proceeds via cyclic or acyclic forms of xylose, the existence of some intermediate compounds is not questionable. The formation of intermediates has been 
considered as the rate-limiting stage in the reaction of furfural formation from xylose. ${ }^{15,18}$ Firstly, it was stated that an essential intermediate is a $2,3-(\alpha, \beta$-) unsaturated aldehyde as formed by a $\beta$-elimination reaction from pentose sugars. ${ }^{\mathbf{1 0 , 1 9 , 2 0}}$ Several other authors explained the reaction to take place via a 1,2-enediol intermediate with subsequent dehydration. ${ }^{\mathbf{4 , 1 8}}$ More recently, the isomerization of aldopentoses to ketose sugar (luxose ${ }^{17,21}$ or xylulose $\mathrm{e}^{22-24}$ ) as an intermediate step in furfural formation has been studied intensively. The current developments of bi-functional catalysts ${ }^{24-28}$ and other catalytic systems ${ }^{29}$ consider an implementation of such two stage process which includes the xylose isomerization as the first step followed by the second step - the ketose sugar dehydration to furfural. However, the role of these intermediate ketose sugars (luxose or xylulose) in the furfural formation reactions remains unclear. Only few studies have focused on the determination of the intermediate xylulose concentration during the process ${ }^{4,27,29}$ and considered its formation and conversion for kinetic parameters evaluation. ${ }^{22}$ The formation of xylulose during xylose conversion in high temperature water has been confirmed in a study made by Aida et $a .^{22}$ with implementation of GC-MS analysis. They observed the formation of about $20 \%$ of $\mathrm{D}$-xylulose at $350-400{ }^{\circ} \mathrm{C}$ after $0.5-1 \mathrm{~s}$ reaction time.

In addition to conventional reactor systems, microwave irradiation can be utilized as an alternative rapid and efficient heating method during furfural production. It has been shown to accelerate reaction rates and to give a slightly higher furfural yield, which is, nonetheless, comparable to the conventional heating methods. ${ }^{12}$ The aim of this study is to devise kinetic models for the non-catalyzed and acid-catalyzed dehydration of xylose to furfural under microwave irradiation at the temperature range $180-220{ }^{\circ} \mathrm{C}$. A special focus is placed to address the role of xylulose in the total reaction scheme.

\section{Experimental}

\section{Materials}

D-Xylose powder ( $\geq 99 \%$, Sigma Aldrich), D-xylulose ( $\geq 98 \%$, syrup, HPLC grade, Sigma Aldrich), furfural (99\%, Sigma Aldrich), sulfuric acid (49-51\%, HPLC grade, Sigma Aldrich) were used in the experiments and as calibration standards as purchased, without further purification. Formic acid (98\%, Sigma Aldrich) and acetic acid (99\%, HPLC grade, Sigma Aldrich) were used for the preparation of calibration standards for HPLC analysis. Millipore grade water was used for the solutions preparation.

\section{Methods}

Single component solutions of D-xylose $\left(51,196,498 \mathrm{mmol} \mathrm{l}^{-1}\right)$, D-xylulose $\left(7 \mathrm{mmol} \mathrm{l}^{-1}\right)$ and furfural $\left(85 \mathrm{mmol} \mathrm{l}^{-1}\right)$ were freshly prepared before experiments. The first set of experiments was performed without addition of sulfuric acid as catalysts. These experiments can be considered as auto-catalyzed reaction system where some side products (namely carboxylic acids) or intermediates, formed during the treatment, may have a catalytic effect. The second set of experiments was performed using $0.1 \mathrm{~mol} \mathrm{l}^{-1} \mathrm{H}_{2} \mathrm{SO}_{4}$ as a catalyst.
The samples were prepared by heating $3 \mathrm{ml}$ of the reaction mixture in a Monowave 300 single-mode microwave reactor (Anton Paar GmbH, Graz, Austria) using a borosilicate glass vial of $10 \mathrm{ml}$ capacity. A magnetic stirrer at $600 \mathrm{rpm}$ utilized to mix the solution during the reaction. Time-to-maximum temperature was set to $1.5 \mathrm{~min}$ with $850 \mathrm{~W}$ maximum output power employed. The temperature inside the reaction vessel was controlled by a fiber optic sensor. The prepared solutions were tested for furfural yield and monosugars conversion at the treatment temperatures of 220,200 and $180{ }^{\circ} \mathrm{C}$ with different reaction times in the range of 1-240 $\mathrm{min}$. The reaction vial was rapidly cooled after the treatment by compressed air inside the reactor. The highest temperature and the longest reaction time studied at the present work were limited to $220^{\circ} \mathrm{C}$ and $240 \mathrm{~min}$, respectively, due to the technical limitations of the Monowave 300 reactor.

The liquid samples were analyzed by High Performance Liquid Chromatography (HPLC) using a Dionex UltiMate 3000 HPLC (Dionex, Sunnyvale, CA, USA) device equipped with refractive index (RI) and ultraviolet (UV) diode array detectors and HyperREZ XP Carbohydrate $\mathrm{Ca}^{+}$column (Thermo Scientific, Waltham, MA, USA). $0.0025 \mathrm{~mol}^{-1}$ sulfuric acid solution was

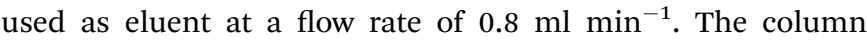
temperature and the RI detector temperature were set to $70{ }^{\circ} \mathrm{C}$ and $55{ }^{\circ} \mathrm{C}$, respectively. The furfural concentration in the liquid samples was determined by UV-detector at wavelength $280 \mathrm{~nm}$, and the residual xylose concentration was analyzed by RI detector. The xylulose concentration was measured by RI-detector with a crosscheck using UV detector at $210 \mathrm{~nm} .^{30}$ The HPLC system was calibrated within the compounds concentrations from 10 to $150 \mathrm{mg} \mathrm{l}^{-1}$.

The following equations have been used for the mathematical evaluation of the obtained results:

$$
\begin{gathered}
Y_{\mathrm{p}}=\frac{c_{\mathrm{p}}}{c_{\mathrm{r}}} \times 100[\%], \\
X_{\mathrm{r}}=\frac{c_{\mathrm{r}}^{\text {in }}-c_{\mathrm{r}}^{\mathrm{f}}}{c_{\mathrm{r}}^{\text {in }}} \times 100[\%], \\
S_{\mathrm{r}}^{\mathrm{p}}=\frac{c_{\mathrm{p}}}{c_{\mathrm{r}}^{\text {in }}-c_{\mathrm{r}}^{\mathrm{f}}} \times 100[\%],
\end{gathered}
$$

where $Y, X, S$ - yield, conversion, and selectivity to product, respectively; $c$ - concentration in $\mathrm{mmol} \mathrm{l}^{-1}$ (the abbreviations to be read as follows: $\mathrm{r}, \mathrm{p}$, in, $\mathrm{f}$ - reactant, product, initial, final).

Reaction kinetics were modelled by nonlinear regression analysis by fitting the simulated ideal batch reactor composition to the experimental one covering xylose, xylulose and furfural molar concentrations. All the computations were implemented in MATLAB 2013b (Mathworks Inc.). The ordinary differential equations were numerically solved by 'ode15s' (variable order method for stiff odes) and optimization to minimize the weighed sum of squared residuals was done by 'fminsearch' (Nelder-Mead algorithm). Weighing factors were applied to compensate the weight of the experiments with very dilute concentration scale. 
The kinetic parameters for each tested reaction temperature were expressed by the following equation:

$$
k_{i}=A_{\text {ref }, i} \exp \left(-\frac{E_{\mathrm{a}, i}}{R}\left(\frac{1}{T}-\frac{1}{T_{\text {ref }}}\right)\right)\left[\mathrm{min}^{-1}\right],
$$

where $T_{\text {ref }}$ and $T[\mathrm{~K}]$ - reference temperature $(473 \mathrm{~K})$ and experimental temperature respectively, $E_{\mathrm{a}, i}\left[\mathrm{~kJ} \mathrm{~mol}^{-1}\right]$ - activation energy, $A_{\text {ref }, i}\left[\mathrm{~min}^{-1}\right]$ - temperature-mean-centered Arrhenius pre-exponential constant.

The plug flow reactor simulations were implemented in MATLAB 2013b. The set of boundary value equations were numerically solved by 'ode23'. Optimization of the temperature and the residence time to maximize the simulated furfural yield was carried out using 'fminsearch' routine.

\section{Results and discussions}

\section{Experimental results}

Un-catalyzed decomposition of xylose. The furfural yield, $\mathrm{pH}$, xylose conversion and xylulose yield at various reaction times for the un-catalyzed $\mathrm{D}$-xylose conversion experiments conducted at 180, 200 and $220^{\circ} \mathrm{C}$ are shown in Fig. 1.

In agreement with previous studies, ${ }^{31-33}$ furfural yield and xylose conversion were observed to be strongly influenced by the treatment temperature. As seen in Fig. 1a, after the first 25-35 min of the treatment the furfural yield was increased up to 4.5-5 times by increasing the temperature from 180 to $200{ }^{\circ} \mathrm{C}$. A further 2-2.5fold increase was observed with the temperature change from 200 to $220{ }^{\circ} \mathrm{C}$.

It was observed that at the highest temperature studied $\left(220^{\circ} \mathrm{C}\right)$ the furfural yield from xylose dehydration goes through a maximum and thereafter decreases with increasing reaction time. The maximum furfural yield (45-48\%) was reached after the first $35 \mathrm{~min}$ at $220{ }^{\circ} \mathrm{C}$, corresponding to a xylose conversion of $96 \%$ (Fig. 1c). However, at the temperature $200{ }^{\circ} \mathrm{C}$ the same conversion was achieved only after 115-125 min resulting in similar maximum furfural yield.

These results are in close agreement with those reported by Möller and Schröder. ${ }^{34}$ The decrease of furfural yield with a further increase in the reaction time can occur due to decomposition $^{35-37}$ and polymerization with char formation. ${ }^{\mathbf{1 0 , 3 8}}$

At the lower reaction temperatures $\left(180\right.$ and $\left.200^{\circ} \mathrm{C}\right)$, no rapid decrease in the furfural yield after certain reaction time was observed during the reaction time range studied. It is, however, possible that a yield decrease similar to that observed at $220{ }^{\circ} \mathrm{C}$ could be observed also at these temperatures during prolonged treatment times. Nevertheless, the maximum yield clearly shifts to a longer reaction time with a decline of the treatment temperature.
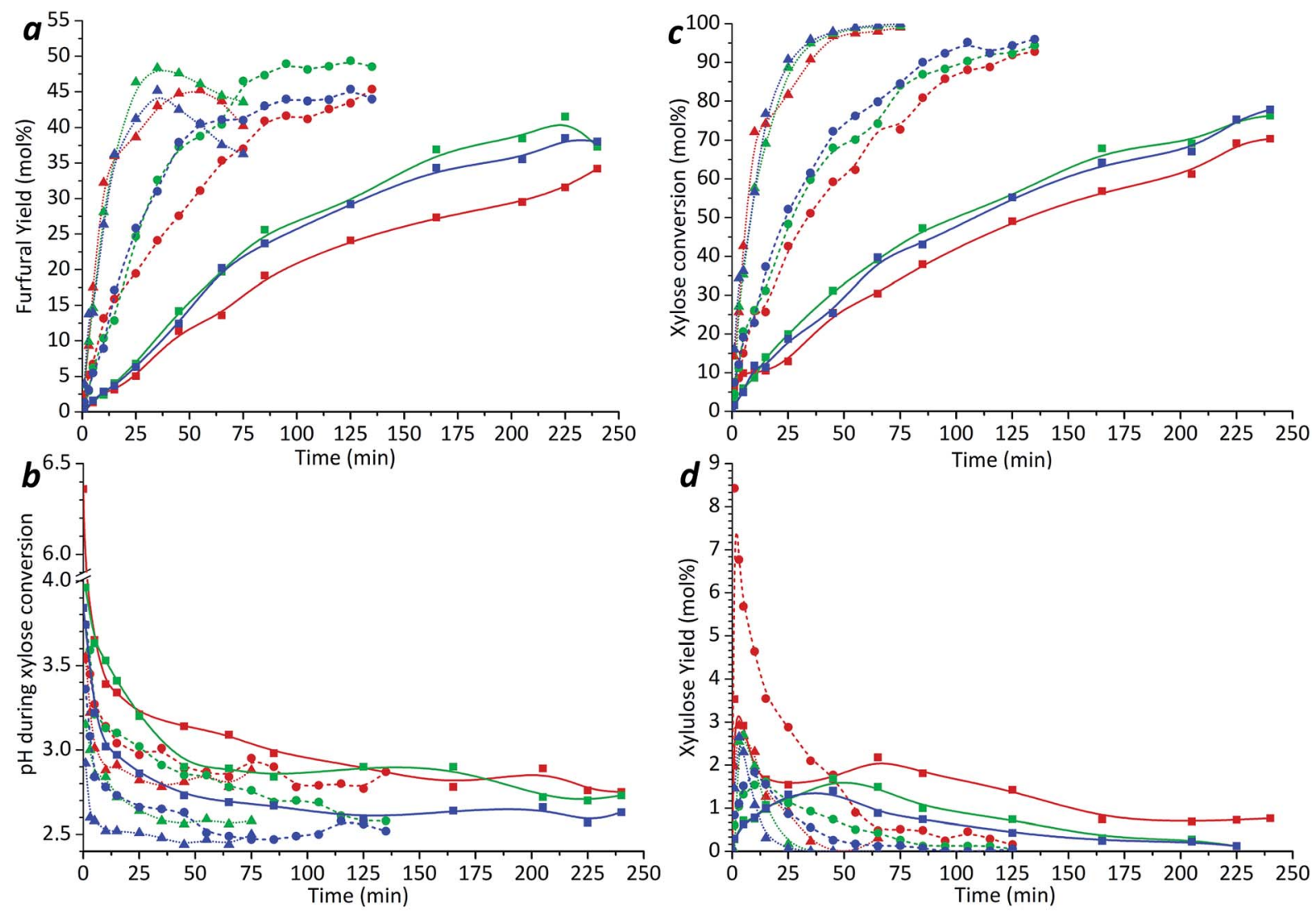

Fig. 1 The furfural yield (a), pH (b), xylose conversion (c) and xylulose yield (d) at various initial xylose concentrations, temperatures and reaction times during un-catalyzed xylose conversion (red $-51 \mathrm{mmol} \mathrm{l} \mathrm{l}^{-1}$ xylose, green $-196 \mathrm{mmol} \mathrm{l^{-1 }}$ xylose, blue $-498 \mathrm{mmol} \mathrm{l^{-1 }}$; square with straight connection line $-180^{\circ} \mathrm{C}$, circle with dashed connection line $-200^{\circ} \mathrm{C}$, triangle with doted connection line $-220{ }^{\circ} \mathrm{C}$ ). 
The maximum selectivity to furfural formation during un-catalyzed xylose conversion was around $48-52 \%$ in the studied range of reaction temperatures. These results are in agreement with the previous reports, ${ }^{31,34}$ indicating either a small or even a negligible effect of microwave irradiation on furfural formation.

The xylose conversion and furfural yield are also dependent on the initial xylose concentration as seen in Fig. 1a and c. The dependence of xylose conversion on the initial concentration is, however, less significant at higher temperatures. During the first 15-25 min of the experiment, both furfural yield and xylose conversion seem to be independent of the initial xylose concentration. However, with extended reaction times, a clear concentration dependence can be observed. The furfural yield increased by $12 \%$ after $100 \mathrm{~min}$ at $200{ }^{\circ} \mathrm{C}$ and $14 \%$ after $175 \mathrm{~min}$ at $180{ }^{\circ} \mathrm{C}$ when the initial concentration of xylose was increased from 51 to $196 \mathrm{mmol} \mathrm{l}^{-1}$. A further increase of the initial xylose concentration to $498 \mathrm{mmol} \mathrm{l}^{-1}$ did not lead to higher furfural production; but, at the temperatures of 200 and $220{ }^{\circ} \mathrm{C}$, it led to a reduction of $5-7 \%$ in the furfural yield in comparison to the experiments with a xylose concentration of $196 \mathrm{mmol} \mathrm{l}^{-1}$ (Fig. 1a). Fig. 1a also shows that at $220^{\circ} \mathrm{C}$, the furfural yield starts to decrease earlier in the solution with increasing initial xylose concentration. This phenomenon could be well explained by a side reaction between furfural and xylose (or intermediate compounds), ${ }^{\mathbf{1 0}, 38}$ which is, probably, promoted by increasing temperature. These results suggest that differences in reaction temperature and other conditions might explain the contradiction between previous reports either concluding the furfural yield to be independent on the xylose concentration $^{\mathbf{1 2}}$ or observing an almost linear decline in furfural yield when initial xylose concentration was increased. ${ }^{\mathbf{1 4 3 9}}$ In the work published by Weingarten et al., ${ }^{12}$ the experiments were performed at relatively low temperatures and very short experimental time, while other authors investigated the furfural formation at more severe conditions including higher temperature, pressure and prolonged reaction time. ${ }^{\mathbf{1 4 , 3 9}}$

As can be seen in Fig. 1b, the pH of the solution decreases rapidly during the first $5 \mathrm{~min}$ of the experiment and levels off at about 3-2.5 in all of the temperatures studied. A similar decrease in $\mathrm{pH}$ has been earlier reported for the xylose degradation in subcritical ${ }^{\mathbf{6 , 4 0}}$ or high temperature ${ }^{\mathbf{4 1}}$ water, and it can be explained by the formation of acidic compounds such as formic, glycolic, lactic and acetic acids ${ }^{41}$ during the degradation of the pentose sugars and furfural. The final $\mathrm{pH}$ is observed to be dependent on the reagents concentrations in the solution. A lower final $\mathrm{pH}$ was obtained in the solution with higher initial xylose concentration, supporting the results of Oefner et al., ${ }^{\mathbf{4 1}}$ who observed the formation of these organic acids with a yield of about $15 \%$ of all xylose conversion products. The generated acidic conditions may promote further furfural formation as well as the formation of side products. ${ }^{\mathbf{4 1 , 4 2}}$

The xylulose formation was monitored by means of HPLC utilizing a pure xylulose solution as a reference. No detectable amounts of xylulose were observed in the initial xylose solutions. Fig. 1d shows that the highest amount of xylulose (3-3.5\%) was formed during the initial stage (the first 1-3 min) of the process. At the temperature of $180{ }^{\circ} \mathrm{C}$, some amount of xylulose was present even after a $4 \mathrm{~h}$ treatment. The extent of xylulose formation was highest for the solution with the lowest initial xylose concentration. As can be seen from Fig. 1d, the highest amount of xylulose formed was experimentally found at $200{ }^{\circ} \mathrm{C}$ with the initial xylose concentration $51 \mathrm{mmol} \mathrm{l}^{-1}$. The obtained results show that the xylulose formation is accelerated by increasing the reaction temperature, particularly from $180{ }^{\circ} \mathrm{C}$ to $200{ }^{\circ} \mathrm{C}$. However, at $220{ }^{\circ} \mathrm{C}$ the presence of furfural in a sufficient amount increases the probability of condensation reactions with xylulose.

Un-catalyzed decomposition of xylulose. Several authors suggested xylulose to be the key intermediate in the reaction of furfural formation from xylose $\mathrm{e}^{22,23}$ and its formation as the limiting step in the furfural formation process. In order to shed some light to the role of xylulose in the subsequent dehydration process to furfural, a pure solution of $7 \mathrm{mmol}^{-1}$ xylulose in Millipore water has been tested in the Monowave300 reactor at temperatures 180-220 ${ }^{\circ} \mathrm{C}$. The results were compared to those obtained from $7 \mathrm{mmol} \mathrm{l}^{-1}$ pure xylose solution and summarized in the Fig. 2.

The maximum furfural yield from xylulose obtained during the un-catalyzed process was $25 \%$, which is almost $10 \mathrm{~mol} \%$ lower than the furfural yield obtained from solution with similar concentration of xylose (Fig. 2a). Xylulose was completely transformed into products after 10-15 min at 220 and $200{ }^{\circ} \mathrm{C}$, respectively (Fig. 2b), while no formation of xylose was detected. However, it is possible that its amount was below the HPLC detection limit. At the same time, the full conversion of xylose was achieved only after $55 \mathrm{~min}$ at $220{ }^{\circ} \mathrm{C}$. The results show that the xylulose is more reactive and converts to furfural and other products faster than xylose giving lower $\mathrm{pH}$ during first $10 \mathrm{~min}$ of the reaction. However, the final $\mathrm{pH}$ of the obtained solutions was very similar in both cases with equal initial concentrations of the xylose and xylulose. This implies that almost equal amount of acids were generated from pentoses during degradation experiments.

The formation of solid products was observed at the latest stages of the reaction experiments. These so-called humin-like substances are formed either by resinification and polymerization reactions of furfural ${ }^{\mathbf{1 0}}$ or by condensation reactions between furfural and pentose. ${ }^{38}$ The obtained results show that xylulose is not a key intermediate in the un-catalyzed furfural formation. Xylulose rather leads to a loss reaction than to furfural formation.

Acid-catalyzed decomposition of xylose and xylulose. The furfural yield and the xylose conversion at various reaction times and temperatures during acid-catalyzed conversion of xylose and xylulose are shown in Fig. 3a-c. As in the un-catalyzed process, the furfural yield and the xylose conversion are strongly influenced by the treatment temperature. The yield of furfural shows a maximum at each experimental temperature, and this maximum is shifted to shorter reaction times with an increase in the temperature. The complete xylose conversion after $2 \mathrm{~min}$ reaction at $220{ }^{\circ} \mathrm{C}$ leads to a maximum furfural yield of about $65 \%$ (Fig. $3 \mathrm{~b}$ ). This result is comparable to one reported previously (62\% at $250{ }^{\circ} \mathrm{C}$ (ref. 17)). Similar to the un-catalyzed process, at a lower reaction temperature, a 

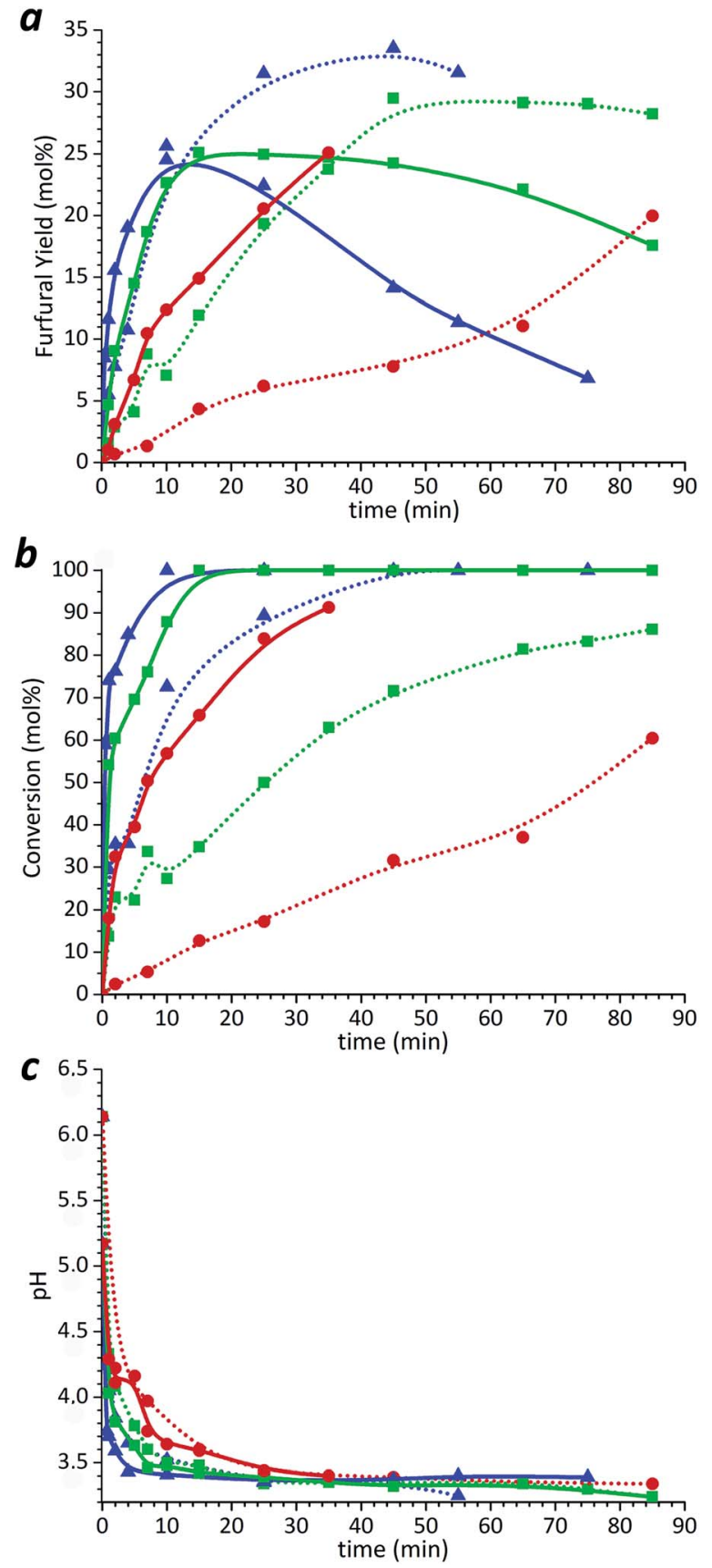

Fig. 2 The furfural yield (a), conversion (b), and $\mathrm{pH}$ (c) at various reaction times during un-catalyzed conversion of xylose and xylulose (red circle $-180{ }^{\circ} \mathrm{C}$, green square $-200{ }^{\circ} \mathrm{C}$, blue triangle $-220^{\circ} \mathrm{C}$; doted connection line - experiments with xylose, straight connection line - experiments with xylulose).

longer reaction time is required to convert the same amount of xylose (Fig. 3c). At the same time it was observed that in the acid-catalyzed process the maximum furfural yield depends on the treatment temperature: it decreases from $65 \%$ to $55 \%$ when temperature is decreased from $220{ }^{\circ} \mathrm{C}$ to $180{ }^{\circ} \mathrm{C}$ (Fig. 3b). A further increase in the reaction time leads to a decrease in the product yield due to furfural decomposition and solid products formation. These furfural yield losses were observed in the whole range of the studied reaction temperatures.
During acid-catalyzed xylose conversion, the maximum selectivity to the furfural formation was around $64 \%$ in contrast to $50-51 \%$ obtained in un-catalyzed reaction system. To investigate the possible furfural formation from xylulose in the presence of the acid catalyst, a solution containing $6.6 \mathrm{mmol} \mathrm{l}^{-1}$ of xylulose and $0.1 \mathrm{~mol} \mathrm{l}^{-1} \mathrm{H}_{2} \mathrm{SO}_{4}$ was tested using the same procedure as for the xylose solution. The results are shown in Fig. 3a. For all the tested temperatures, the maximum furfural yield produced was $58-59 \%$ and it was obtained in less than $2 \mathrm{~min}$. This maximum yield is almost 2.4 times higher than in the case of the un-catalyzed system. In the range of the studied reaction temperatures, the complete xylulose conversion during the acid-catalyzed reaction was achieved already after $1 \mathrm{~min}$ treatment. At the time when all the xylulose was converted, a part of formed furfural was already degraded. The furfural yields from xylulose in acidcatalyzed reactions obtained in previous studies were 40-50\% (ref. 4) at $96{ }^{\circ} \mathrm{C}, 50-65 \%$ (ref. 27) at temperatures 105-135 ${ }^{\circ} \mathrm{C}$ using $0.1 \mathrm{~mol} \mathrm{l}^{-1} \mathrm{HCl}$, and $70 \%$ (ref. 29) at $110-130{ }^{\circ} \mathrm{C}$ with $\mathrm{HCl}$ at $\mathrm{pH} 1$.

After acid-catalyzed conversion, neither formation of xylulose from xylose nor formation of xylose from xylulose was detected by HPLC. However, it is possible that the amounts were below the detection limit.

The results of the acid-catalyzed process suggest that two different reaction pathways of furfural formation from pentoses possibly coexist. In the un-catalyzed xylose conversion, the intermediate xylulose seemingly leads to the side products formation, while with the addition of sulfuric acid a prevailing mechanism includes fast ketose dehydration to furfural.

Furfural degradation. In order to extend the understanding about the behavior of furfural under the conditions used in the microwave-assisted reaction, knowledge on its degradation rate is needed. The furfural degradation experiments were performed for the un-catalyzed as well as for the acid-catalyzed reactions using $85 \mathrm{mmol} \mathrm{l}^{-1}$ furfural solution at the temperatures of 180,200 and $220^{\circ} \mathrm{C}$. The experimental data showing the remaining fractions of furfural at various reaction times are presented in Fig. 4.

Fig. 4 illustrates the effect of the treatment temperature and the usage of $0.1 \mathrm{~mol} \mathrm{l}^{-1} \mathrm{H}_{2} \mathrm{SO}_{4}$ as catalyst on the degradation rate of furfural. The results show a clear dependency of furfural degradation on the temperature, similarly to the data presented in earlier reports..$^{\mathbf{3 1 , 3 6 , 3 7 , 4 2 , 4 3}}$ It can be seen that the implementation of a higher temperature increases the furfural degradation for both un-catalyzed and acid-catalyzed reactions. In addition, the results show that furfural is decomposed more rapidly in the presence of $0.1 \mathrm{~mol} \mathrm{l}^{-1} \mathrm{H}_{2} \mathrm{SO}_{4}$. The highest degree of degradation, $68 \%$, was observed at $220{ }^{\circ} \mathrm{C}$ after $35 \mathrm{~min}$ in $0.1 \mathrm{~mol} \mathrm{l}^{-1}$ sulfuric acid solution. Without the acid catalyst, only $15 \%$ of furfural was converted at the same temperature and reaction time. The formation of furfural resinification products - humins - was observed at the late stages of both un-catalyzed and acid-catalyzed degradation. The acetic and formic acids were also found in the solution during non-catalyzed and acidcatalyzed furfural degradation reactions. 

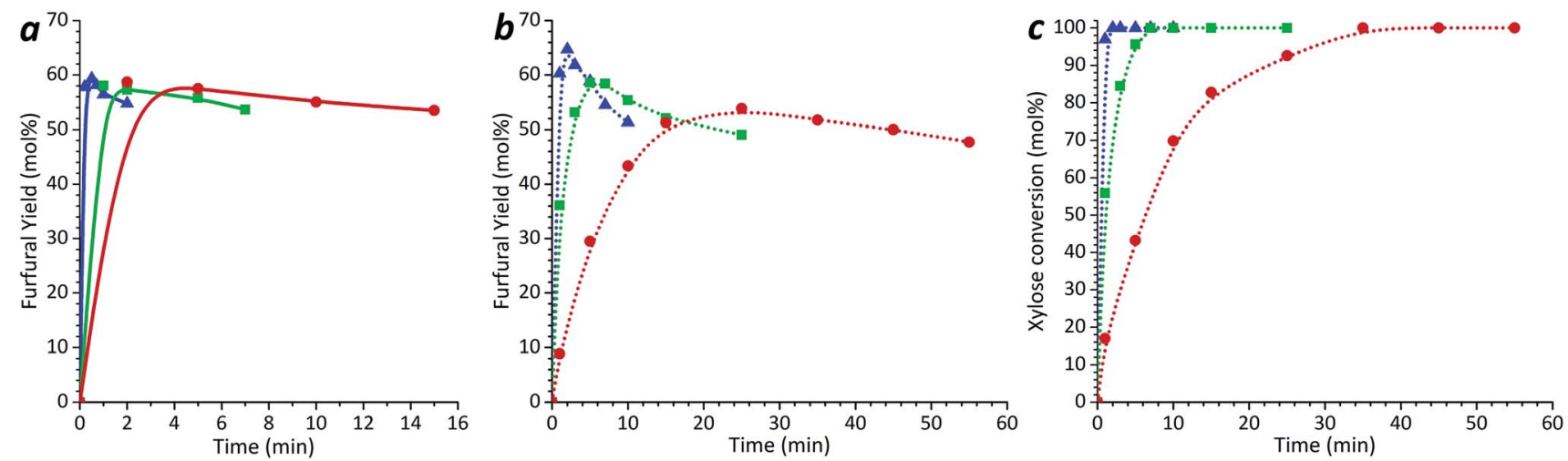

Fig. 3 The furfural yield from xylulose (a), xylose (b) and xylose conversion (c) at various reaction times during acid-catalyzed conversion of xylose and xylulose (red circle $-180^{\circ} \mathrm{C}$, green square $-200^{\circ} \mathrm{C}$, blue triangle $-220^{\circ} \mathrm{C}$; doted connection line - experiments with xylose, straight connection line - experiments with xylulose).

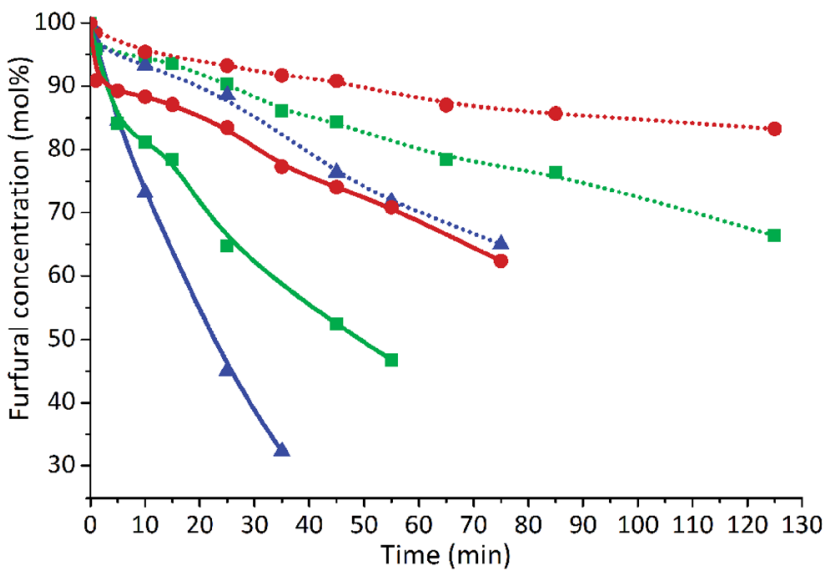

Fig. 4 The remaining furfural concentration at various reaction times during un-catalyzed and acid-catalyzed degradation (red circle $-180^{\circ} \mathrm{C}$, green square $-200^{\circ} \mathrm{C}$, blue triangle $-220^{\circ} \mathrm{C}$; doted connection line - un-catalyzed process, straight connection line $-0.1 \mathrm{~mol} \mathrm{l}^{-1} \mathrm{H}_{2} \mathrm{SO}_{4}$ added as catalyst).

\section{Reaction mechanism and its mathematical modelling}

Based on the obtained experimental results, several reaction mechanisms were screened in order to find the optimal kinetic model explaining the xylose dehydration and furfural formation. The model screening was performed by formulating mechanism candidates, implementing corresponding mathematical models and by carrying out nonlinear regression analysis to test the compatibility of a model to the experimental data and to receive values for kinetic parameters. These reaction mechanisms considered a pathway of furfural formation pathways from xylose via intermediate xylulose or tentatively via some other intermediates to furfural. Using the xylose conversion data only in the modeling resulted in multiple equally wellfitting models with differing mechanistic assumptions. Therefore, the data set was appended with the independent xylulose conversion and furfural degradation experiments that enabled the model screening and mathematical identification of the values for all the related rate constants. Finally, the best fitting of the model to experimental data was obtained taking into account pathways via xylulose and via another intermediate compound leading to the formation of furfural in the un-catalyzed and the acid-catalyzed reactions. The developed reaction mechanism taking into account the xylulose formation from xylose is as follows:

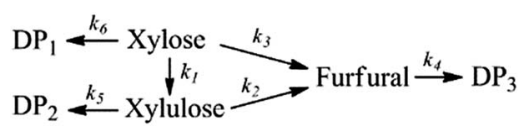

In the reaction model presented in eqn (5), xylose can be converted to furfural either stepwise with xylulose as an intermediate product $\left(k_{1}+k_{2}\right)$, or via a direct or pseudo-direct reaction pathway $\left(k_{3}\right)$, which may involve the formation of some other intermediate compound but not xylulose. The produced furfural further forms degradation products $\left(\mathrm{DP}_{3}\right)$. At the same time, some parts of the xylose and xylulose form degradation products, $\mathrm{DP}_{1}$ and $\mathrm{DP}_{2}$, respectively. The possible side reactions between xylose and furfural ${ }^{10,44}$ and the isomerization of xylulose back to xylose were not identifiable from the present data.

Assuming a sequence of pseudo-first order reactions, ${ }^{22,41}$ the proposed reaction model can be expressed by differential equations as follows:

$$
\begin{gathered}
\frac{\mathrm{d}[\text { xylose }]}{\mathrm{d} t}=-\left(k_{1}+k_{3}+k_{6}\right)[\text { xylose }], \\
\frac{\mathrm{d}[\text { xylulose }]}{\mathrm{d} t}=k_{1}[\text { xylose }]-\left(k_{2}+k_{5}\right)[\text { xylulose }], \\
\frac{\mathrm{d}[\text { furfural }]}{\mathrm{d} t}=k_{2}[\text { xylulose }]+k_{3}[\text { xylose }]-k_{4}[\text { furfural }],
\end{gathered}
$$

where $k_{1}$ is the rate constant of xylose isomerization to xylulose; $k_{2}$ and $k_{3}$ are the rate constants of furfural formation from xylulose and xylose, respectively; $k_{4}, k_{5}$ and $k_{6}$ are the degradation rate constants for furfural, xylulose and xylose, respectively.

The fits of the proposed kinetic model for acid-catalyzed and un-catalyzed reactions are shown in Fig. 5 and 6, respectively. 
The fitting is relatively good for all experimental series with different initial xylose concentration ranging from 50 to $500 \mathrm{mmol} \mathrm{l}^{-1}$. The model reconciles all the xylose conversion data as well as the independent experiments for xylulose conversion and furfural degradation. This indicates that the reaction behavior of furfural and monosugars at high temperatures can be adequately predicted by first order kinetic model. It should be noted that the validity of first-order models may be attributed to the relatively dilute concentrations and nonsimultaneous presence of abundance of furfural and sugars. To the author's knowledge in some solutions, relevant in industry, the high xylose concentration, e.g. 1.5-2 $\mathrm{mol} \mathrm{l}^{-1}$, have a strong impact on the furfural yield. Future experiments targeting at the investigation of the influence of the initial xylose concentration on furfural formation encompassing a much broader concentration range need to be carried out in order to elucidate the effect of initial xylose concentration on furfural formation.

The obtained kinetic parameters and the activation energies for the each reaction step are shown in Tables 1-3. Some literature data for the kinetic parameters related to similar reaction steps are shown for comparison in Tables 2 and 3.

As seen from Table 1, the implementation of sulfuric acid as a catalyst leads to an increase of more than one order of magnitude for all the reaction rates in comparison to the respective step in the un-catalyzed process. As an exception, the rate constants for the xylose isomerization to xylulose $\left(k_{1}\right)$ are of the same order of magnitude in both catalytic and non-catalytic systems. This observation is supported by the fact that sugar isomerization reactions are catalyzed by Lewis acids ${ }^{24,26}$ or bases ${ }^{18}$ but not by sulfuric acid.

The rate constants for un-catalyzed and catalyzed reactions are evaluated at experimental temperatures to be able to elucidate relative contributions of individual steps (Table 1). The temperature dependence of $k_{i}$ is more pronounced in the acidcatalyzed processes, indicating that the reaction rates in the absence of sulfuric acid are less sensitive to the reaction temperature.
This is in line with the activation energies given in Table 2. The ratio of the reaction rate constants $k_{2} / k_{3}$ shows that in both reaction types furfural formation is more than six times faster from xylulose than from xylose. At the same time, the high ratio $k_{2} / k_{1}$ indicates that the xylulose formation from xylose can be considered as the rate-limiting step in furfural production via this reaction pathway. The values of $k_{3} / k_{1}$ show a substantial difference between the un-catalyzed and acid-catalyzed processes. The rate of the xylose isomerization to xylulose during un-catalyzed process is comparable to the rate of furfural formation from xylose ( $k_{3} / k_{1}$ is near to 1$)$, whereas in the acidcatalyzed process isomerization is substantially slower in these two competing reactions $\left(k_{3} / k_{1}\right.$ values from 44.5 to 5.3$)$.

From these results, it can be concluded that the addition of $0.1 \mathrm{~mol} \mathrm{l}^{-1} \mathrm{H}_{2} \mathrm{SO}_{4}$ shifts the xylose conversion reaction towards furfural formation via some other intermediate than xylulose. For the acid-catalyzed reactions, the role of xylulose formation in the furfural production is insignificant in the range of studied reaction conditions.

The ratios $k_{5} / k_{6}$ and $k_{5} / k_{4}$ for the un-catalyzed and acidcatalyzed reactions reveals that at temperatures $180-220{ }^{\circ} \mathrm{C}$ xylulose is intend to degradation reaction more than xylose and furfural. Moreover, the ratio $k_{5} / k_{2}$ indicates that in un-catalyzed process the degradation of xylulose is three times more preferable than its conversion to furfural. However, when sulfuric acid is added as a catalyst, about $70 \%$ of the reacting xylulose is dehydrated to furfural. However, as the isomerization rate from xylose to xylulose is rather low in the acid catalyzed case the overall role of xylulose as an intermediate remains modest.

The calculated frequency factors and activation energies for proposed kinetic model for un-catalyzed and acid-catalyzed conversions are presented in Tables 2 and 3, respectively.

To the authors' knowledge, the activation energies of xylose isomerization to xylulose, furfural and degradation products formation from xylulose have not been previously reported in literature for neither un-catalyzed nor acid-catalyzed reactions. Aida et al. ${ }^{22}$ have presented respective rate constants, but only for the temperatures of 350 and $400{ }^{\circ} \mathrm{C}$. The high temperature difference and implementation of high pressure by Aida et al.
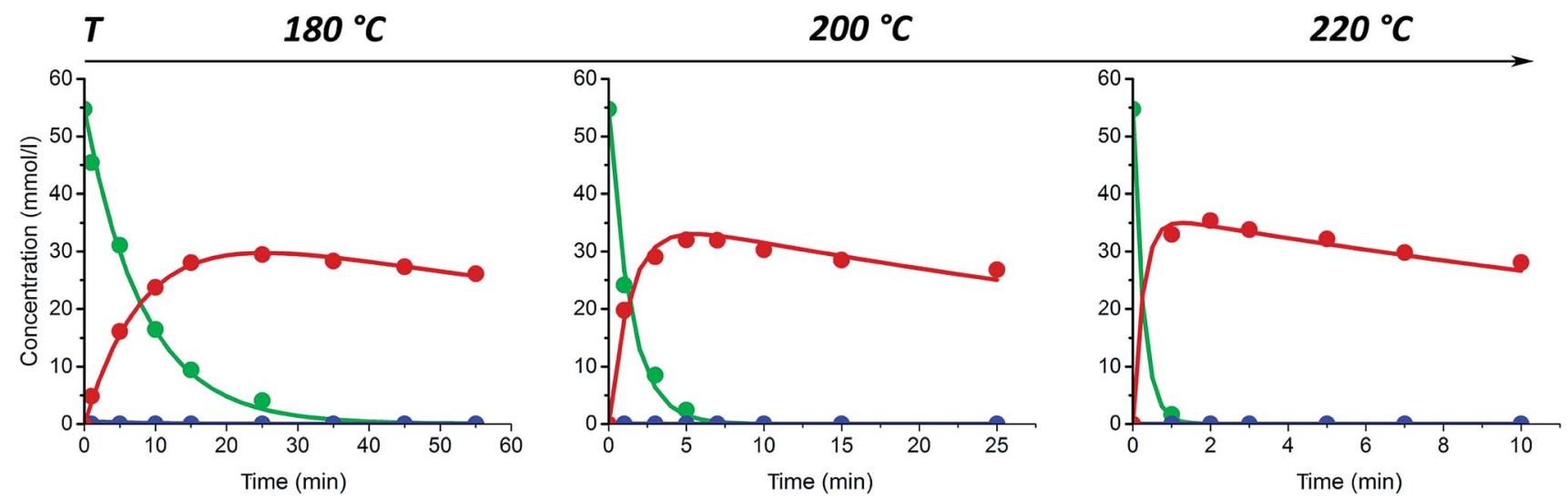

Fig. 5 Experimental (circle) and modeled (solid lines) concentrations of xylose, furfural and xylulose at different temperatures in acid-catalyzed conditions (green - xylose, red - furfural, blue - xylulose). 

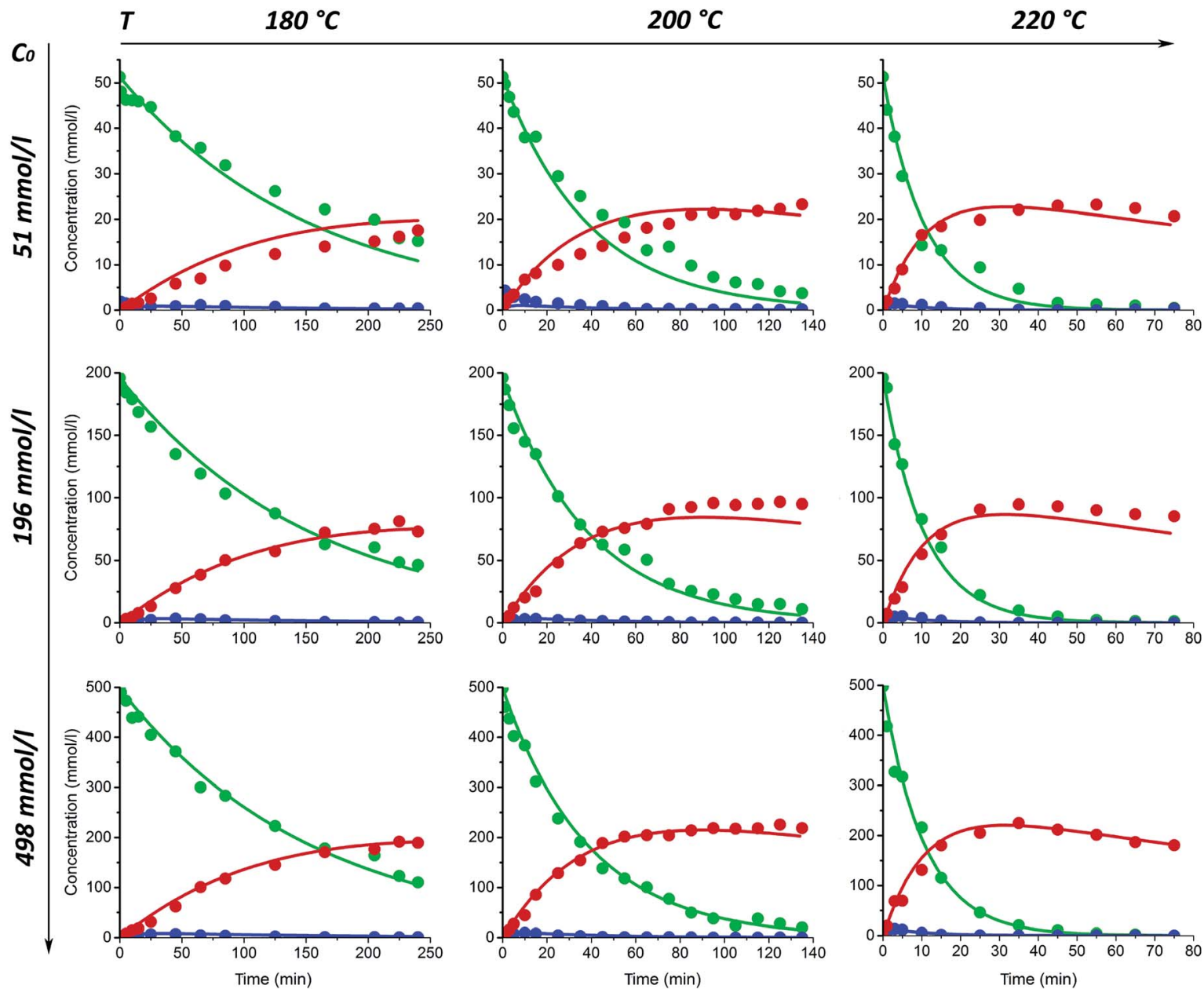

Fig. 6 Experimental (circle) and modeled (solid lines) concentrations of xylose, furfural and xylulose at different temperatures and initial xylose concentrations in un-catalyzed conditions (green - xylose, red - furfural, blue - xylulose).

makes their results incomparable with the values obtained in this work.

As seen from Tables 2 and 3 the higher activation energies of steps 2 and 3 in case of the catalysed reactions in comparison to the uncatalysed ones reveals that furfural formation is favored at higher temperatures in the case of catalyzed reactions. This fact is supported by the results in Fig. 1 and $3 a$ and b.

As seen in Table 3, the activation energy of furfural formation from xylose $\left(113.2 \mathrm{~kJ} \mathrm{~mol}^{-1}\right)$ obtained in our work is in a good agreement with the results previously published by Jing and $L \ddot{u}^{31}$ and Chen et al. ${ }^{40}$ The activation energy of furfural degradation $\left(53.5 \mathrm{~kJ} \mathrm{~mol}^{-1}\right)$ is also in a good agreement with data published by Jing and $\mathrm{Lü},{ }^{31}$ which can be expected because of the similarity in the experimental and procedure design.

As it can be seen from Table 3, the activation energies calculated for the acid-catalyzed process in the present study are much higher than those published earlier., ${ }^{3,12,41,45}$ These discrepancies between data could be possibly explained by

Table 1 Kinetic rate constants $k_{i}\left(\mathrm{~min}^{-1}\right)$ at each experimental temperature for un-catalyzed and acid-catalyzed systems and ratio of selected rate constants

\begin{tabular}{|c|c|c|c|c|c|c|c|c|c|c|c|c|c|}
\hline$T,\left({ }^{\circ} \mathrm{C}\right)$ & Acid & $k_{1}$ & $k_{2}$ & $k_{3}$ & $k_{4}$ & $k_{5}$ & $k_{6}$ & $k_{3} / k_{1}$ & $k_{2} / k_{3}$ & $k_{2} / k_{1}$ & $k_{5} / k_{6}$ & $k_{5} / k_{2}$ & $k_{5} / k_{4}$ \\
\hline 220 & - & 0.039 & 0.268 & 0.042 & 0.0059 & 1.016 & 0.013 & 1.1 & 6.4 & 6.9 & 79.8 & 3.8 & 172.1 \\
\hline 200 & - & 0.009 & 0.081 & 0.013 & 0.0034 & 0.270 & 0.004 & 1.5 & 6.2 & 9.1 & 73.0 & 3.3 & 79.4 \\
\hline 220 & + & 0.056 & 16.151 & 2.499 & 0.0315 & 11.214 & 1.235 & 44.5 & 6.5 & 287.8 & 9.1 & 0.69 & 355.7 \\
\hline 200 & + & 0.028 & 4.100 & 0.450 & 0.0150 & 2.800 & 0.230 & 16.1 & 9.1 & 146.4 & 12.2 & 0.68 & 186.7 \\
\hline 180 & + & 0.013 & 0.922 & 0.070 & 0.0067 & 0.619 & 0.037 & 5.3 & 13.2 & 70.2 & 16.7 & 0.67 & 92.5 \\
\hline
\end{tabular}


Table 2 Frequency factors $\left(A_{\text {ref, } i} \mathrm{~min}^{-1}\right)$ and activation energies $\left(E_{\mathrm{a}, i}, \mathrm{~kJ} \mathrm{~mol}{ }^{-1}\right)$ for the kinetic model proposed in eqn (5); un-catalyzed system

\begin{tabular}{llll}
\hline$i$ & $A_{\text {ref, } i}$ & $E_{\mathrm{a}, i}$ & $E_{\mathrm{a}, i}$, literature data \\
\hline 1 & 0.0089 & 143.2 & - \\
2 & 0.0810 & 116.1 & - \\
3 & 0.0130 & 113.2 & 76.6 (ref. 14), 111.5 (ref. 31), 110-127 (ref. 40), 119.4 (ref. 41), 129.9 (ref. 13) \\
4 & 0.0034 & 53.5 & 24.2 (ref. 14), 36.5 (ref. 6), 58.8 (ref. 31), 75.5 (ref. 47) \\
5 & 0.2700 & 128.5 & - \\
6 & 0.0037 & 119.8 & 58.8 (ref. 14), 101-119 (ref. 22), 143.1 (ref. 31), 168.5 (ref. 13)
\end{tabular}

Table 3 Frequency factors $\left(A_{\text {ref }, i, m^{-1}}\right)$ and activation energies $\left(E_{\mathrm{a}, i}, \mathrm{~kJ} \mathrm{~mol}^{-1}\right)$ for the kinetic model proposed in eqn (5); acid-catalyzed system with $0.1 \mathrm{~mol} \mathrm{l}^{-1} \mathrm{H}_{2} \mathrm{SO}_{4}$

\begin{tabular}{llcl}
\hline$i$ & $A_{\mathrm{ref}, i}$ & $E_{\mathrm{a}, i}$ & $E_{\mathrm{a}, i}$, literature data \\
\hline 1 & 0.03 & 67.4 & - \\
2 & 4.10 & 132.9 & - \\
3 & 0.45 & 166.2 & 123.9 (ref. 12), 126.8 (ref. 3), 120.6-130.8 (ref. 41) \\
4 & 0.02 & 72 & 48.1 (ref. 46), 67.6 (ref. 12), 83.6 (ref. 36), 92.3 (ref. 44), 102-115 (ref. 42 and 43 ), 125.1 (ref. 37) \\
5 & 2.80 & 134.5 & - \\
6 & 0.23 & 162.9 & 148 (ref. 45)
\end{tabular}

either utilization of simplified reaction mechanism ${ }^{3,12-14,31,41,45}$ or implementation of subcritical and supercritical reaction conditions ${ }^{22}$ in the earlier studies.

\section{Plug flow reactor simulations for xylose conversion}

The determined kinetics for uncatalyzed and acid-catalyzed system (Table 1) were utilised to simulate a flow reactor system described by the plug flow reactor model (PFR). The objective was to assess possibilities to maximize the furfural yield by adjusting the reactor residence time and the temperature. A steady state and isothermal operation were assumed. The PFR model with the determined kinetics incorporated for each component is expressed as:

$$
\begin{gathered}
\frac{1}{t} \frac{\mathrm{d}[\text { xylose }]}{\mathrm{d} z}=\left(-k_{1}-k_{3}-k_{6}\right)[\text { xylose }] \\
\frac{1}{t} \frac{\mathrm{d}[\text { xylulose }]}{\mathrm{d} z}=\left(k_{1}[\text { xylose }]-\left(k_{2}+k_{5}\right)[\text { xylulose }]\right) \\
\frac{1}{t} \frac{\mathrm{d}[\text { furfural }]}{\mathrm{d} z}=\left(k_{2}[\text { xylulose }]+k_{3}[\text { xylose }]-k_{4}[\text { furfural }]\right)
\end{gathered}
$$

where a component's name in brackets corresponds to its molar concentration ( $\mathrm{mmol} \mathrm{l}^{-1}$ ), $z$ is the dimensionless axial coordinate of the reactor and $t$ is the reactor residence time ( $\mathrm{min})$, i.e. the reactor volume divided by the volumetric flow rate. The temperature affects the outcome via Arrhenius dependencies of the rate constants $k_{i}$. The numerical simulations provide the molar concentrations as a function of reactor axial coordinate. The key quantity for simulations was chosen to be the furfural yield (mol\%), calculated from the reactor outlet composition. The yield quantity covers both the efficient usage of the reactant xylose and its selectivity to the targeted product. The investigated ranges in the simulations were chosen to be temperatures from $200{ }^{\circ} \mathrm{C}$ up to $280{ }^{\circ} \mathrm{C}$ and residence times between one second up to $150 \mathrm{~min}$. In the simulations, a constant feed concentration of $200 \mathrm{mmol} \mathrm{l}^{-1}$ of xylose was assumed.

Simulation results revealed that for the uncatalyzed system the optimal process parameters are $T=218^{\circ} \mathrm{C}$ and $t=34.8 \mathrm{~min}$ which resulted in $44.34 \%$ furfural yield. Fig. 7 illustrates the furfural yield as a function of the residence time and the reaction temperature. As can be seen, in addition to the reported optimum, there is a relatively wide region of temperature and time combinations that provide a furfural yield above $40 \%$.

In comparison to the un-catalyzed system, the strong acidcatalyzed system behaved differently in PFR simulations. The

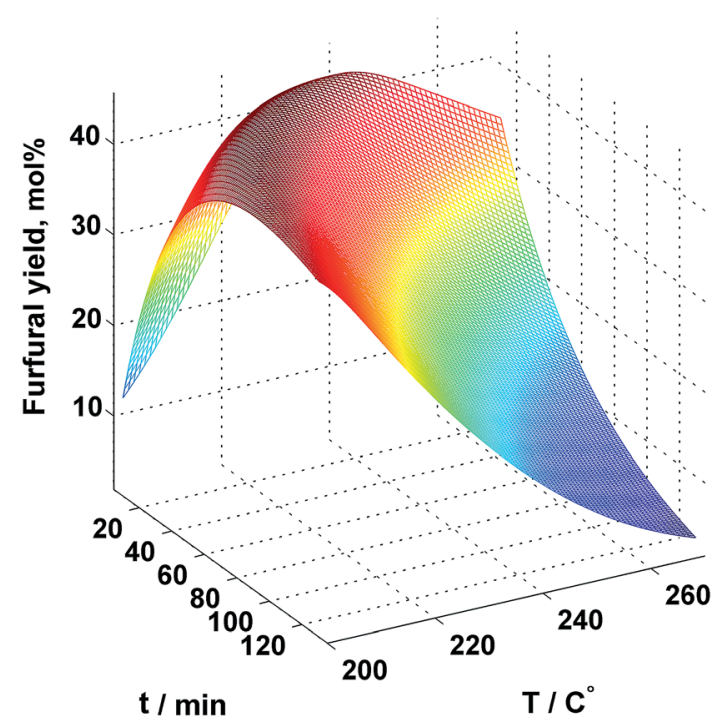

Fig. 7 Simulated furfural yield as a function of residence time and temperature for uncatalyzed xylose conversion in plug flow reactor. 
Table 4 Plug flow reactor simulated at selected temperatures for strong acid catalyzed xylose conversion. The residence times have been optimized for maximal furfural yields at the chosen temperatures

\begin{tabular}{lll}
\hline$T,{ }^{\circ} \mathrm{C}$ & $t, \min$ & $Y$ (furfural) $\mathrm{mol} \%$ \\
\hline 200 & 5.3 & 60.4 \\
220 & 1.3 & 64.0 \\
230 & $0.62=37 \mathrm{~s}$ & 65.1 \\
240 & $0.31=18.6 \mathrm{~s}$ & 66.1 \\
250 & $0.16=9.6 \mathrm{~s}$ & 66.7 \\
260 & $0.084=5.0 \mathrm{~s}$ & 67.4 \\
270 & $0.045=2.7 \mathrm{~s}$ & 67.9 \\
280 & $0.025=1.5 \mathrm{~s}$ & 68.3
\end{tabular}

highest furfural yield was calculated for the maximum allowed temperature and with extremely short residence time. Table 4 displays the maximum furfural yields at selected temperatures and the required residence times for each temperature for attaining the optimal yield. The simulation results suggest that operating a PFR for $65 \%$ furfural yield requires the residence time slightly below 40 seconds at the temperature of $230{ }^{\circ} \mathrm{C}$. Further increase in temperature and decrease in residence time can promote the furfural yield further up to $68 \%$, provided that the extrapolation from $220^{\circ} \mathrm{C}$ and $280^{\circ} \mathrm{C}$ is valid. The dynamics of the strong acid catalyzed xylose conversion in a flow system would call for small-diameter-devices such as millireactors or, alternatively, an efficiently heat-controlled section in a tubular reactor followed by an efficient effluent cooling.

The plug flow reactor simulations underline how the uncatalyzed and strong acid catalyzed kinetics define the theoretical bounds for harnessing the intrinsic kinetics for furfural production, and they simply illustrate the interplay between the temperature and the residence time in flow systems for optimizing the furfural yield. If a yield of $44 \mathrm{~mol} \%$ is considered acceptable, furfural production could be implemented without catalysts. On the other hand, $68 \mathrm{~mol} \%$ cannot likely be exceeded without either inventive furfural recovery strategies or the inhibition of the loss reactions related to furfural and xylose.

\section{Conclusions}

The broad and informative experimental data were collected under well-controlled conditions and utilized for kinetic modeling of both the non-catalyzed and acid-catalyzed dehydration of xylose. A reaction mechanism with six kinetically relevant steps was found to be the most compatible with all the collected experimental data under microwave irradiation in the temperature range of $180-220^{\circ} \mathrm{C}$. The reaction steps were best described with the first order dynamics. The determined kinetic parameters were well identified and of physically meaningful order of magnitudes. Mechanism and parameter identification relied on the versatility in the experimental data: independent xylulose conversion and furfural degradation experiments provided a critical additional information in the combination with the xylose conversion experiments started at three initial concentrations and at three reaction temperatures.
Xylulose was identified during the xylose conversion in varying yields depending on the reaction conditions, especially on the temperature. In the light of the results obtained, the role of xylulose as a key intermediate for furfural production from xylose was rejected under the tested reaction conditions. The experimental data obtained for the un-catalyzed xylose conversion as such ruled out the possibility of xylulose being the key intermediate. Modeling helped to establish the role of xylulose along a parallel reaction pathway. The primary reaction route involves another short-living intermediate that reacts rapidly to the furfural.

The results of the batch reactor experiments in conjunction with the plug-flow reactor simulations suggest that the maximum obtained furfural yield for the un-catalyzed system remains below $50 \%$ and requires approximately 35 minutes at $220{ }^{\circ} \mathrm{C}$ or 90 minutes at $200{ }^{\circ} \mathrm{C}$. The presence of a strong acid accelerates most of the reaction steps and increases the maximum furfural yield. In the batch reactor experiments the maximum furfural yield of $62-65 \mathrm{~mol} \%$ was obtained corresponding to $2-3 \mathrm{~min}$ reaction time at $220^{\circ} \mathrm{C}$ in the acid catalyzed case. The plug flow reactor simulations for the acid catalyzed conversion suggested furfural yields up to $68 \mathrm{~mol} \%$ with further increase in the reaction temperature along with an appropriate reduction in the residence time in the continuous operation.

\section{Acknowledgements}

The authors would like to acknowledge financial support from The International Doctoral Programme in Bioproducts Technology (PaPSaT) and from the Academy of Finland. We also sincerely thank Rita Hatakka for her contribution in the HPLC method development.

\section{References}

1 D. Win, AU Journal of Technology, 2005, 8, 185-190.

2 A. Mittal, S. G. Chatterjee, G. M. Scott and T. E. Amidon, Chem. Eng. Sci., 2009, 64, 3031-3041.

3 E. Garrett and B. Dvorchik, J. Pharm. Sci., 1969, 58, 813-820. 4 T. Ahmad, L. Kenne, K. Olsson and O. Theander, Carbohydr. Res., 1995, 276, 309-320.

5 X. Lü and S. Saka, J. Supercrit. Fluids, 2012, 61, 146-156.

6 X. Bai, X. Liu, F. Xu and R. Li, Adv. Mater. Res., 2014, 512-515, 366-370.

7 R. Lehnen, B. Saake and H. Nimz, Holzforschung, 2001, 55, 199-204.

8 K. C. Schuster, et al., Nat. Fibers, Plast. Compos., 2004, 123-148. 9 T. Zhang, R. Kumar and C. E. Wyman, RSC Adv., 2013, 3, 9809-9819.

$10 \mathrm{~K}$. Zeitsch, The chemistry and technology of furfural and its many by-products, Elsevier Science B.V., 2000.

11 W. Jong de and G. Marcotullio, Int. J. Chem. React. Eng., 2010, 8, 1-25.

12 R. Weingarten, J. Cho, W. C. Conner, Jr and G. W. Huber, Green Chem., 2010, 12, 1423. 
13 M. Borrega, K. Nieminen and H. Sixta, Bioresour. Technol., 2011, 102, 10724-10732.

14 S. B. Kim, et al., React. Kinet., Mech. Catal., 2011, 103, 267-277.

15 B. Danon, G. Marcotullio and W. de Jong, Green Chem., 2014, 16, 39.

16 M. J. Antal, W. S. Mok and G. N. Richards, Carbohydr. Res., 1990, 199, 111-115.

17 M. J. Antal, T. Leesomboon and W. S. Mok, Carbohydr. Res., 1991, 217, 71-85.

18 M. Feather and J. Harris, Adv. Carbohydr. Chem. Biochem., 1973, 28, 161-224.

19 C. Hurd and L. Isenhour, J. Am. Chem. Soc., 1932, 54, 317-330.

20 W. Bonner and M. Roth, J. Am. Chem. Soc., 1959, 81, 5454-5456.

21 R. O'Neill, M. N. Ahmad, L. Vanoye and F. Aiouache, Ind. Eng. Chem. Res., 2009, 48, 4300-4306.

22 T. M. Aida, N. Shiraishi, M. Kubo, M. Watanabe and R. L. Smith, J. Supercrit. Fluids, 2010, 55, 208-216.

23 J. Binder, J. Blank, A. Cefali and R. Raines, ChemSusChem, 2010, 3, 1268-1272.

24 V. Choudhary, S. Caratzoulas and D. G. Vlachos, Carbohydr. Res., 2013, 368, 89-95.

25 A. Takagaki, M. Ohara, S. Nishimura and K. Ebitani, Chem. Lett., 2010, 39, 838-840.

26 V. Choudhary, A. B. A. Pinar, S. I. S. Sandler, D. G. Vlachos and R. F. Lobo, ACS Catal., 2011, 1, 1724-1728.

27 V. Choudhary, S. I. Sandler and D. G. Vlachos, ACS Catal., 2012, 2, 2022-2028.

28 M. Shirotori, S. Nishimura and K. Ebitani, Catal. Sci. Technol., 2014, 4, 971.

29 B. Li, S. Varanasi and P. Relue, Green Chem., 2013, 15, 2149.

30 S. Givry, C. Bliard and F. Duchiron, Carbohydr. Res., 2007, 342, 859-864.
31 Q. Jing and X. Lü, Chin. J. Chem. Eng., 2007, 15, 666-669.

32 B. Shen, Y. Liu and J. Peng, Adv. Mater. Res., 2013, 690-693, 1382-1385.

33 P. Brazdausks, N. Vedernikovs, M. Puke and I. Kruma, Key Eng. Mater., 2014, 604, 245-248.

34 M. Möller and U. Schröder, RSC Adv., 2013, 3, 22253.

35 A. Dunlop, Ind. Eng. Chem., 1948, 40, 204-209.

36 D. Williams and A. Dunlop, Ind. Eng. Chem., 1948, 40, 239-241.

37 G. Marcotullio and M. Cardoso, Int. J. Chem. React. Eng., 2009, 7, 1-14.

38 I. V. Sumerskii, S. M. Krutov and M. Y. Zarubin, Russ. J. Appl. Chem., 2010, 83, 320-327.

39 K. Gairola and I. Smirnova, Bioresour. Technol., 2012, 123, 592-598.

40 X. Chen, X. Liu, F. Xu and X. Bai, Adv. Mater. Res., 2014, 450451, 710-714.

41 P. J. Oefner, A. H. Lanziner, G. Bonn and O. Bobleter, Monatsh. Chem. Chem. Mon., 1992, 123, 547-556.

42 K. Lamminpää, J. Ahola and J. Tanskanen, RSC Adv., 2014, 4, 60243-60248.

43 B. Danon, L. van der Aa and W. de Jong, Carbohydr. Res., 2013, 375, 145-152.

44 D. Root, J. F. Saeman, J. F. Harris and W. K. Neill, For. Prod. J., 1959, 158-165.

45 E. S. Kim, S. Liu, M. M. Abu-Omar and N. S. Mosier, Energy Fuels, 2012, 26, 1298-1304.

46 I. C. Rose, N. Epstein and A. P. Watkinson, Ind. Eng. Chem. Res., 2000, 39, 843-845.

47 K. Lamminpää, J. Ahola and J. Tanskanen, Ind. Eng. Chem. Res., 2012, 51, 6297-6303. 